\title{
Spatial evolution of coal transportation at coastal ports in China
}

\author{
WANG Wei ${ }^{1,2,3}$, "WANG Chengjin ${ }^{1}$, JIN Fengjun ${ }^{1}$ \\ 1. Institute of Geographic Sciences and Natural Resources Research, CAS, Beijing 100101, China; \\ 2. University of Chinese Academy of Sciences, Beijing 100049, China; \\ 3. School of Geography, Beijing Normal University, Beijing 100875, China
}

\begin{abstract}
Coal is a basic resource and its use guarantees the development of national economies and human society. Thus, coal transportation is an important part of China's overall transportation system. In this system, ports are the vital transit nodes. This study considered coastal ports in China and analysed the evolution of coal transportation from 1973 to 2013. We focused on the spatial pattern of coal loading and unloading, and summarized the main characteristics and development of the processes. Then, we examined the volumes of coal transported and regional changes in these amounts using mathematical models and indicators. Finally, we analysed the specialized function and spatial differentiation of the ports involved in coal transportation to reveal their spatial relationship and temporal evolution. We found that the spatial pattern of coal transportation changed from "south input and north output" to "all input and north output". However, the prominent ports used for coal unloading are still concentrated in areas south of the Yangtze River. Coal loading is concentrated on the west bank of Bohai Bay. In addition, some ports around Bohai Bay, such as Dandong, Dalian, Yantai, and Qingdao, changed from traditional coal loading ports to unloading ports. This study further developed the theory of transport geography, and improved our understanding of China's coal transportation system.
\end{abstract}

Keywords: coastal ports; coal transportation; spatial differentiation; spatial evolution; loading and unloading

\section{Introduction}

Coal is the main energy resource in China and is an important industrial material. It provides about $70 \%$ of the country's energy and more than $60 \%$ of the raw materials used by industry. In the next ten years, the heavy chemical industry will continue to grow and the consumption of coal will also expand. The country's coal-dominated energy consumption structure cannot be changed for quite a long time. Therefore, consideration should be given to the

Received: 2016-11-22 Accepted: 2017-01-11

Foundation: National Natural Science Foundation of China, No.41571113, No.41771134, No.41701126; Strategic Priority Research Program of CAS: Evaluation of Connectivity of Infrastructure Network and Spatial Optimization

Author: Wang Wei, $\mathrm{PhD}$, specialized in transport geography and regional development studies.

E-mail: wang21600@163.com

"Corresponding author: Wang Chengjin, Professor, specialized in economic geography and transport geography.

E-mail: cjwang@igsnrr.ac.cn 
supply and transportation network of coal resources (Cai and Zhang, 2006). Many studies have been conducted worldwide on coal transportation and supply. Some have compared the cost of different transportation modes to determine the optimum systems, such as identifying the best ways to transport coal from west to east in Canada (Ash and Waters, 1991), and comparing the cost of coal transportation in the American West Highlands by slurry pipeline and railway (Kania, 1984). The relationship between coal transportation and the geographical environment is an interesting research field. Socio-economic systems and topography are important factors that can affect coal transportation; in particular, the spatial structure of existing transport networks directly determines the pattern of allocation of coal resources (Elmes, 1984). Mathematical models have been used to depict coal flows from the coal supply base to the consumption base. Some studies have analysed the coal flow in America (Leblanc et al., 1978). Many studies have also considered the global coal logistics network (Zaklan et al., 2012). Research in different countries has had a different emphasis because of the different spatial relationship between coal distribution and socio-economic systems. China is rich in coal resources, but also has a huge demand for coal consumption. Coal production and transport are of great significance to China's social and economic development (Todd, 1997). Previous studies have considered the spatial and temporal coordination of the national energy supply (Zhang et al., 2012), investigated the spatial and temporal pattern and undertaken a potential evaluation of the development of China's energy resources (Ma et al., 2010), and analysed China's coal supply and future output (Wang et al., 2013). These studies have evaluated the developmental pattern of coal resources in China. The spatial mismatch between the coal supply base and the consumption market has prompted many researchers to consider interregional allocation and the transporting of coal resources (Yu et al., 2006). Some studies of the spatial and temporal variation of the coal satisfaction rate, self-sufficiency rate, and external satisfaction rate have been conducted (Ma and Jin, 2014). Many studies have considered the evolution of the spatial flow pattern of coal resources and the factors that have influenced its development in China (Zhao and Yu, 2007; Cheng et al., 2008; Wang et al., 2009; Che et al., 2014; Wang and Zhao, 2014). The development of transport corridors and their routes are also important issues that have been investigated. Researchers have systematically analysed the current situation and development of the coal trade and its transport corridors in China (Wang and Ducruet, 2014), with a focus on the optimization of the distribution of the corridors (Wei, 2008; Liu et al., 2013) and the railway network (Ji and Zhao, 2014; Jiang et al., 2013). There have been few studies of coal transportation at ports. Existing studies have mainly focused on two aspects. One is the forecasting of coal throughput at ports (Liu et al., 2014), while the other is research regarding specific ports or areas; for example, studies of the current situation with regard to coal transportation in the ports of Qinhuangdao and Tianjin (Yang, 2011; Yu, 2012), investigating the logistical coal capacity of ports in Tianjin and Hebei Province (Dong and Wang, 2012), and considering the evolution and dynamic mechanisms of coal transportation for the ports around Bohai (Wang and Wang, 2014).

In summary, previous studies have mainly focused on the pattern of coal exploitation, the interregional allocation, and transportation by the rail network. Few studies have focused on coal transportation through ports, especially on the spatial pattern and evolution of coal transportation of China's coastal ports using long-term data. Therefore, this study considered 
the characteristics and evolution of coal transportation at China's coastal ports using data collected since the 1970s. The aim was to identify and summarize any spatial patterns, investigate the relationship between loading and unloading, and to obtain a better understanding of China's coal transportation system.

\section{Data and methods}

\subsection{Data and samples}

This study used coal transportation data for China's coastal ports and some related economic indicators. The coal transportation data was coal throughput, and loading and unloading volumes, while the economic indicators were mainly performance data for high coal consumption industries, which reflect the demand for coal. The coal transportation data for China's coastal ports were obtained from the Yearbook of China Transportation and Communications, published by China's Ministry of Transport. A small number of data were obtained from port portals. Related economic data were taken from the China Statistical Yearbook. The study considered the period from 1973 to 2013. As the focus of the study, we selected coastal ports in China, of which there are 57 according to the National Plan for Coastal Port Layout (Figure 1). In the Yangtze River Delta, we followed the traditional definition, in which ports below Nanjing are considered to be ocean ports.

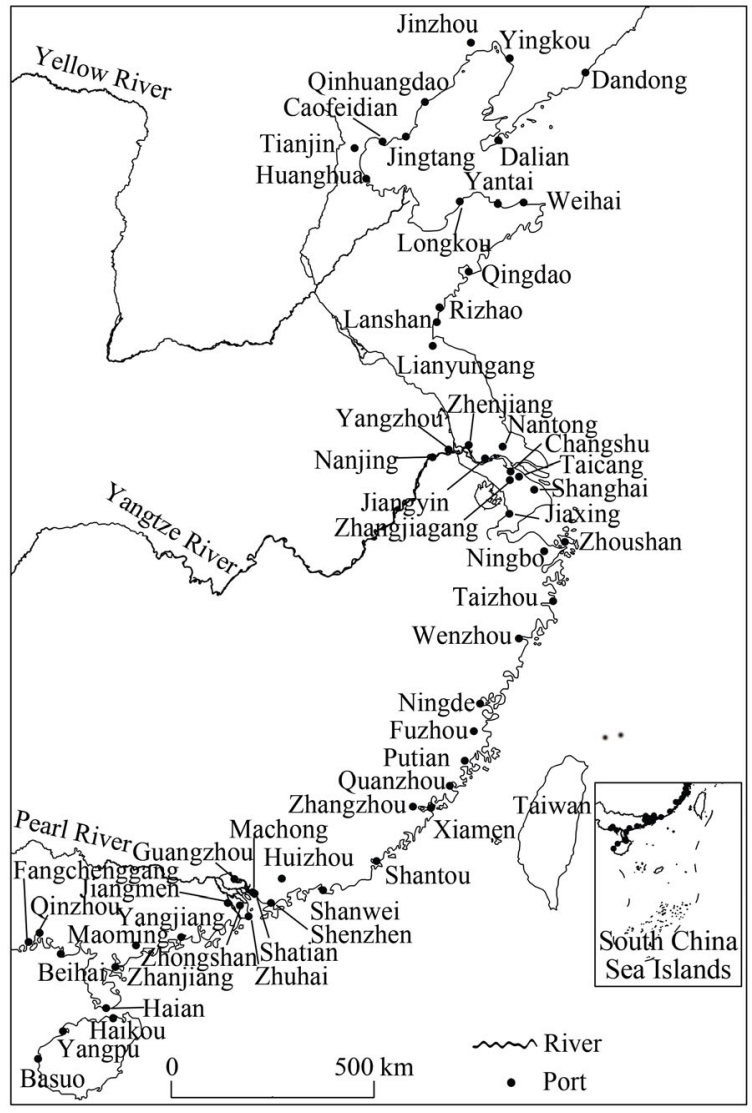

Figure 1 Coastal ports in China

\subsection{Evaluation model}

National coal transportation at ports is a complex spatial system involving many different ports. Each port has different levels of dominance and throughput. Furthermore, there is not only coal loading, but also coal unloading occurring at individual ports, which can reflect the relationship between regional development and the supply and demand of coal. To examine the complexity of coal transportation and reveal the characteristics of spatial variation, we measured indexes based on three aspects: the spatial agglomeration level of port coal transportation, intensity of specialized function, and the relationship between loading and unloading in the same port. 
Agglomeration is an important spatial concept in geography. It can reflect the spatial non-equilibrium of resources and economic activities. An agglomeration analysis of coal transportation is beneficial to the study of spatial structure and can identify the characteristics of spatial variation of coal transportation system. It can also reveal the status and function of different ports in the coal transportation and national economic network. The Herfindahl-Hirschman Index (HHI) is an effective method used to measure spatial agglomeration; thus, we used it to evaluate the spatial agglomeration of coal transportation. The formula used in the calculation is as follows:

$$
H H_{i}=\sum_{i=1}^{n}\left(X_{i} / T\right)^{2}
$$

where $X_{i}$ is the coal throughput or the volume of coal loaded and unloaded at port $i$, and $T$ is the total throughput or the volume of coal loaded and unloaded at all coastal ports. The range of $H H_{i}$ is $[0,1]$. The closer to zero the value is, the lower the level of spatial agglomeration is.

The $H H_{i}$ index can only evaluate the macro-spatial structure of port coal transportation. It cannot be used to determine the status and hierarchy of each port in the whole system. A location quotient is required. The cargo location quotient is the ratio of the proportion of a certain type of cargo in a single port to its proportion among all coastal ports in the country. It can reflect the level of specialization of the port toward coal transportation and the standard of the terminal facilities. The formula used in the calculation is as follows:

$$
Q_{i j}=\frac{t_{i j} / t_{i}}{T_{j} / T}=\frac{t_{i j} / \sum_{j=1}^{n} t_{i j}}{\sum_{i=1}^{m} t_{i j} / \sum_{i=1}^{m} \sum_{j=1}^{n} t_{i j}}
$$

where $Q_{i j}$ is the location quotient of cargo $j$ for port $i, t_{i j}$ is the throughput of cargo $j$ for port $i$, $t_{i}$ is the throughput of port $i, T_{j}$ is the throughput of cargo $j$ for all coastal ports, and $T$ is the total throughput of all coastal ports. If $Q_{i j} \leqslant 1$, then port $i$ does not have specialized functions in the transportation of this cargo. If $Q_{i j}>1$, cargo $j$ is the specialized cargo for port $i$, and the larger the value is, the stronger the specialized functions of the port are.

Although the location quotient of coal can be used to investigate the transportation advantages of an individual port, it cannot be used to determine the relationship between coal loading and unloading at the same port. This relationship reflects different aspects of regional development and the supply and demand of coal. Thus, we constructed the $R_{i}$ index to evaluate the relationship between the loading and unloading of coal. The formula used in the calculation is as follows:

$$
R_{i}=T_{i j e} / T_{i j}=T_{i j e} /\left(T_{i j e}+T_{i j f}\right)
$$

where $T_{i j e}$ is the volume of coal loaded at port $i$, and $T_{i j f}$ is the volume of coal unloaded at port $i$. The range of $R_{i}$ is $[0,1]$. The closer to 1 the value is, the higher the level of coal loaded at the port is.

\section{Spatial evolution of coal loading and unloading at China's coastal ports}

The transportation of any goods involves both an origin and a destination. Most of the coal 
throughput at China's ports is domestic. Coal loading and unloading takes place at different ports in China. The different coal loading and unloading ports reflect the spatial relationship between ports, the coal supply base, coal consumption market, and shipping routes. An investigation of the spatial pattern and evolution of coal loading and unloading ports can help us to understand the pattern and mechanism of coal transportation in China.

\subsection{Spatial pattern and evolution of coal loading}

Port coal loading refers to the transportation of coal to ports by road and then the outward shipping of the coal. A port is not only the starting point of the coal shipping process, but is also the gateway of land transportation of coal. The location, throughput, and spatial agglomeration level of coal loading ports can reflect the relationship between ports, the coal supply base, and transportation corridors. In this study, we systematically established the volume of coal loaded at China's coastal ports (see Figure 2).

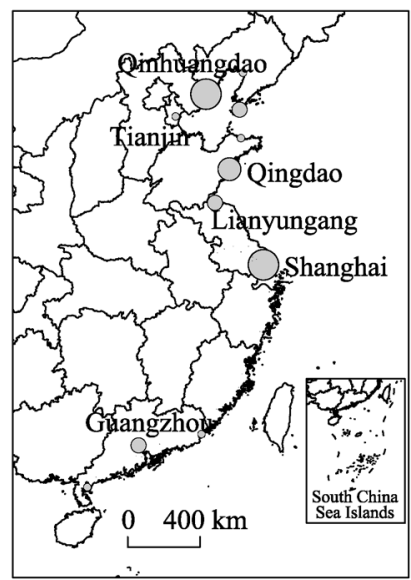

(a) 1973

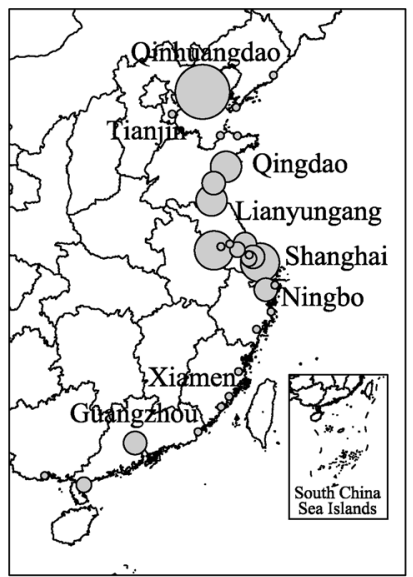

(b) 1986

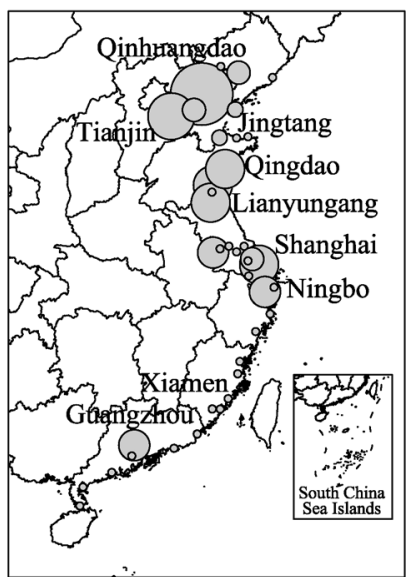

(c) 1995

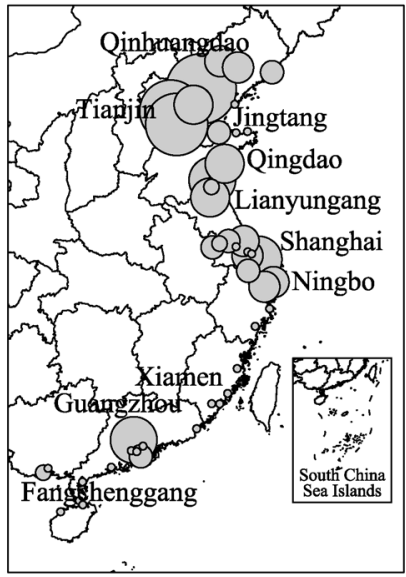

(d) 2005

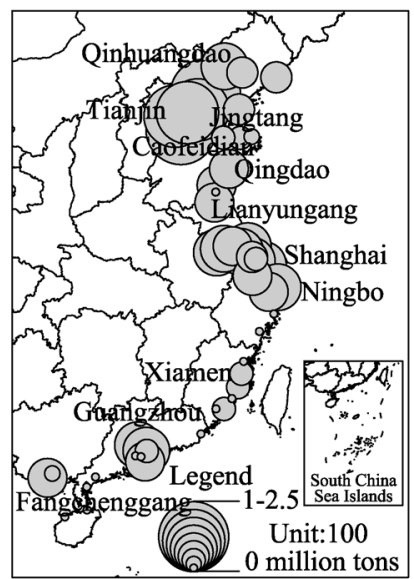

(e) 2013

Figure 2 Spatial pattern and evolution of coal loading at coastal ports in China, 1973-2013

Since the 1970s, the pattern of coal loading at China's coastal ports has roughly evolved in four stages. Each stage had a different number of ports, area served by ports, loading scale, and level of activity as a proportion of national port activity. In the first stage, in the early 
1970s, there were only 11 coal loading ports: Qinhuangdao, Shanghai, Qingdao, Lianyungang, Dalian, Guangzhou, Yantai, Zhanjiang, Tianjin, Shantou, and Yingkou. The scale of coal loading was very small at only 14.47 million tons in 1973. Qinhuangdao and Shanghai loaded larger volumes of 5.04 and 4.07 million tons, respectively. A "north output" pattern of coal loading ports began to appear. During the second stage, in the mid-1980s, the number of coal loading ports gradually increased, especially in the Yangtze River Delta. There were 29 ports in this period. The volume of coal loaded was 75.74 million tons in 1986. Qinhuangdao loaded the largest volume of coal in China at 31.50 million tons, which represented $42 \%$ of the national total. In Shanghai 13.50 million tons were loaded, and the difference in the volume loaded between Qinhuangdao and Shanghai continued to increase. There was a high degree of spatial agglomeration and the loading volume was concentrated on the west bank of Bohai Bay, the south of Shandong Peninsula, and the Yangtze River Delta. A "north output" pattern officially formed, which resulted from the output of the three western districts of the three provinces region (Shanxi, Shaanxi, and Inner Mongolia Autonomous Region). Since the beginning of the third stage in the 1990s, the number of coal loading ports increased rapidly. There were 39 ports in 1995, in which a total volume of 152 million tons of coal was loaded. At 12 ports, more than one million tons of coal was loaded. Qinhuangdao handled the largest volume of 64.88 million tons, accounting for $42.7 \%$ of the national total. The volume handled at Tianjin, Rizhao, and Shanghai was more than 10 million tons. This was closely related to the rising volume of coal exported, which accounted for more than $25 \%$ of the loading volume in these ports. The volume of coal loaded continued to increase on the west bank of Bohai Bay and the south of Shandong Peninsula, while at the Yangtze River Delta the volume remained relatively stable. The coal output function of northern ports continued to strengthen. In the fourth stage, since the $21^{\text {st }}$ century, the volume of coal loaded increased at a faster rate. It was 414 million tons in 2005 and 914 million tons in 2013. Coal exports decreased rapidly during this period due to the tightening of the resource export policy and the implementation of an energy security strategy. Therefore, growth in the coal loading volume was mainly due to the rapid increase in domestic trade. The number of ports was 49 , with 34 where the volume of coal loaded was more than one million tons. Qinhuangdao was still the largest coal loading port in China, handling around $40 \%$ of the national total, but there was a downward trend in later years, with the figure decreasing to $25.8 \%$ in 2013 . The volume of coal loaded at Huanghua port increased to 130 million tons, accounting for $14.5 \%$ of the national total. Tianjin, Jingtang, and Caofeidian each accounted for $9 \%$. The five ports with the largest volumes of coal loaded in 2013 were located on the west bank of Bohai Bay, and together accounted for $67.3 \%$ of the national total. Therefore, the "north output" pattern of coal loading did not change and continues to develop on the west bank of Bohai Bay. The agglomeration level of the Yangtze River Delta and south of Shandong Peninsula increased. The volume of coal loaded in the ports in the Pearl River Delta also increased. There was a rapid increase in the volume of coal loaded in the Beibu Gulf ports, especially in Fangchenggang where the volume increased from 0.64 million tons in 2005 to 11.63 million tons in 2013. The enhancement of the coal loading function of ports in the Pearl River Delta and the Beibu Gulf was mainly due to the secondary distribution of imported coal. 


\subsection{Spatial pattern and evolution of coal unloading}

Port coal unloading refers to the transport of coal from other ports. In this system, a port is the landing gateway to the onward transportation of coal to various regions. The distribution and scale of coal unloading ports reflects not only coal transportation routes, but also the location and scale of the coal consumption market. In this study, we systematically established the volume of coal unloaded at China's coastal ports (see Figure 3).

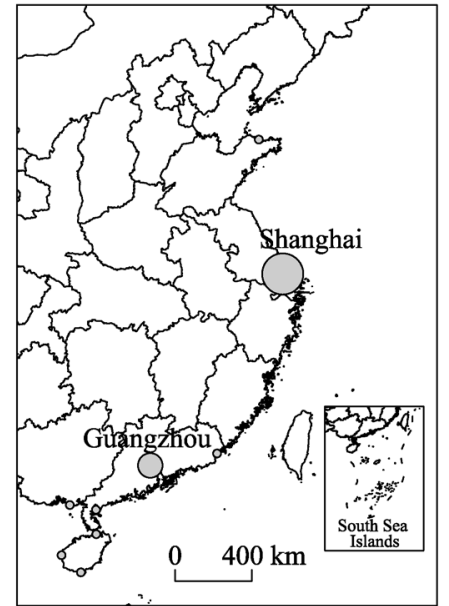

(a) 1973

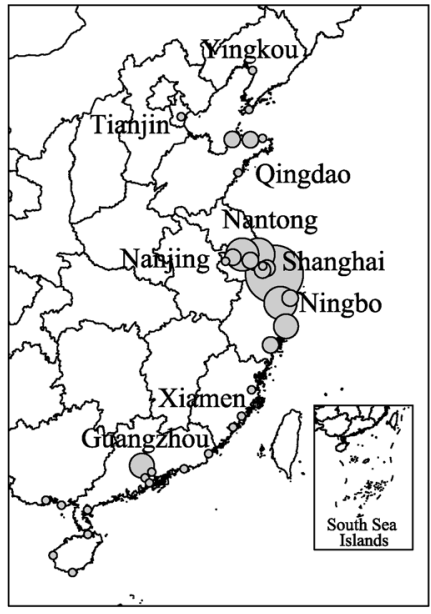

(b) 1986

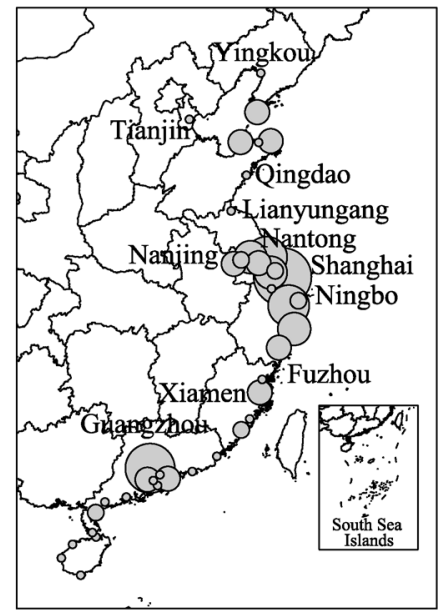

(c) 1995

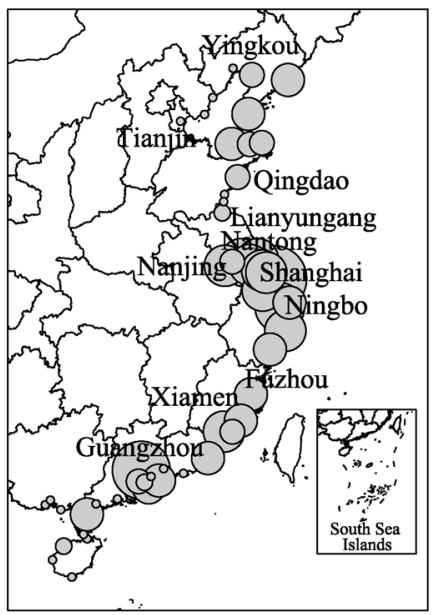

(d) 2005

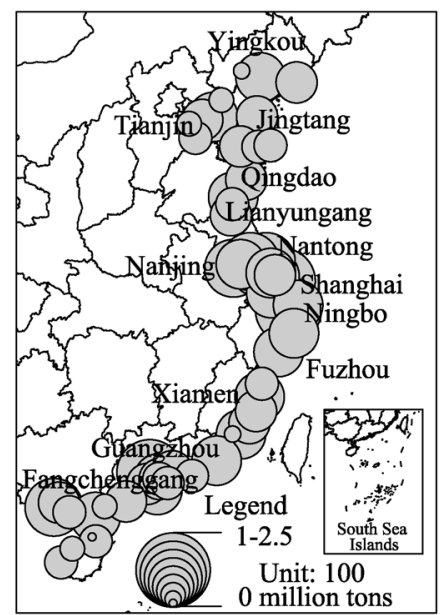

(e) 2013

Figure 3 Spatial pattern and evolution of coal unloading at coastal ports in China, 1973-2013

We can determine the following characteristics from Figure 3. (1) Scattered and isolated southern ports were initially involved in coal unloading, but it gradually began to occur at all coastal ports; i.e., a move from a "south input" pattern to an "all input" pattern. The number of coal unloading ports continued to expand, and unloading coal became the transportation function of most ports. This is consistent with the growth trend of China's coal imports, and also reflects that coal brought in through ports was widely used as an energy supply in coastal areas. Due to the rapid increase in the number of coal unloading ports over time, the total volume of coal unloaded grew rapidly, but the difference in the scale at each port was 
relatively small. (2) In the early 1970 s, there were only nine coal unloading ports: Shanghai, Guangzhou, Zhanjiang, Shantou, Haikou, Basuo, Beihai, Yantai, and Sanya. These ports were mainly distributed in southern China and a "south input" pattern began to appear. The volume of coal unloaded was small, at only 12.89 million tons. Shanghai had the largest volume, accounting for $88.3 \%$ of the national total. (3) In the middle of the $1980 \mathrm{~s}$, the number of ports was 35. They were concentrated in the Yangtze River and southern regions, especially in the Yangtze and Pearl river deltas. There was a small increase in the number of northern ports where coal was unloaded. The volume of coal unloaded increased to 56.73 million tons. Shanghai accounted for $57 \%$ of the national total, while the other ports made quite small contributions. During this period, China's coal imports were small and grew slowly. The "south input" pattern of coal unloading was strengthened. This was because there were few coal resources in the southeast coastal area of China, but its developed economy and dense population consumed large amounts of electric power. The importation of coal from other regions was the main energy supply mode for this area. (4) The volume of coal unloaded continued to increase. It reached 110 million tons in 1995, and the number of coal unloading ports increased to 41 . There were 16 ports where the volume of coal unloaded was more than one million tons. Shanghai was the largest, accounting for $38 \%$ of the national total. In terms of the spatial pattern, coal unloading was concentrated in the Yangtze River Delta, followed by the Pearl River Delta, the Shandong Peninsula, and the Liaodong Peninsula. An "all input" pattern began to appear. (5) Since the middle of the 1990 s, the demand for coal increased due to rapid economic growth. Domestic trade and the import of coal experienced strong and rapid growth. China's coal imports exceeded 200 million tons in 2012 and 300 million tons in 2013. In 2011, China surpassed Japan to become the world's largest coal importer. There was explosive growth in the volume of coal unloaded in coastal ports since the new century, with the volume exceeding 200 million tons in 2004, 300 million tons in 2005, 400 million tons in 2007, and 900 million tons in 2013. The number of coal unloading ports was 57 . All of the large and medium sized ports in the country began to unload coal. The volume of coal unloaded in the northern ports grew rapidly. In addition to the Yangtze River Delta and southeast Fujian, the volume of coal unloaded in the Beibu Gulf and the Pearl River Delta also increased. The "south input" pattern became an "all input" pattern. There were 32 ports where the volume of coal unloaded exceeded 10 million tons in 2013. Shanghai was still the largest port, accounting for $8.8 \%$ of the national total, although this represented a large decline compared with the early period. At Ningbo and Guangzhou, more than 50 million tons of coal were unloaded, accounting for $7.5 \%$ and $5.5 \%$ of the national total, respectively. A comparison of 2013 and 2005 revealed a trend for rapid expansion in the volume of coal unloaded at ports around Bohai Bay. These ports became not only coal loading ports, but also unloading ports. At this point, the "all input" pattern of coal unloading of China's coastal ports was completed.

\section{Spatial agglomeration of coal transportation at China's coastal ports}

\subsection{The evolution of spatial agglomeration at all coastal ports}

As a special type of bulk cargo, the transportation of coal cannot be evenly distributed. With 


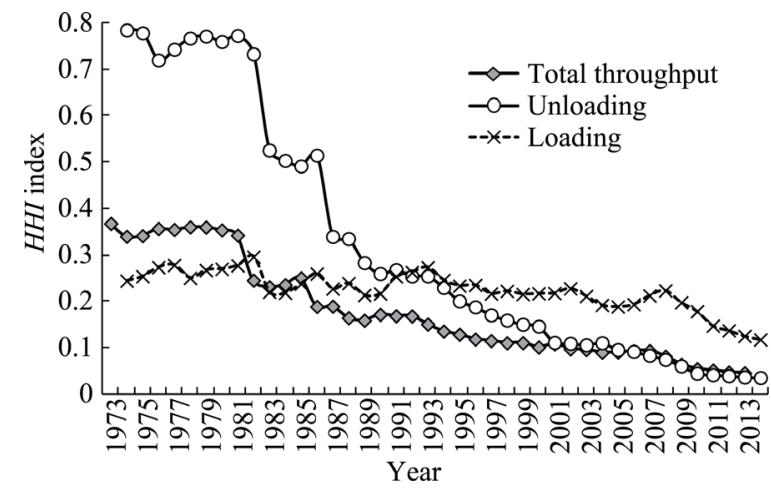

Figure 4 Herfindahl-Hirschman Index $(H H I)$ index values for total throughput, and the loading and unloading of coal at coastal ports in China, 1973-2013 the construction of new ports and the improvement of transportation routes, as well as yield changes in the coal base, the coal transportation functions of each port displayed different growth trends. The trend toward the spatial agglomeration of coal transportation reflects the role of different ports in coal transportation and the national economic network. It can be used to examine the relationship between ports and regional development. As shown in Figure 4, the HHI index values for coal throughput, and the volume loaded and unloaded displayed a significant downward trend during 1973 to 2013. The level of spatial agglomeration of coal transportation decreased. More explicitly, the three curves of the $H H I$ index shown in Figure 4 decreased rapidly and significantly before the end of the 1980s, while afterwards, they showed a steady downward trend and a smaller decline. This indicates that coal throughput, and the volume loaded and unloaded were eventually distributed among many different ports, and the phenomenon of concentrating activity in a few ports gradually weakened. The changes in the early part of this period were due to the increase in the number of ports, while the changes in the late period were due to changes in the volume of coal handled at each port. The $H H I$ index value for coal loading was lower than that for throughput and unloading before the 1980s, but thereafter it was higher than that of throughput, and after the 1990s it was higher than the value for unloading. This indicates that the level of spatial agglomeration for coal loading was higher. The phenomenon of concentrating activity at a few ports was more prominent. This is consistent with the analysis above.

(1) Coal throughput: The coal throughput of China's coastal ports was higher in the 1970s than later in the study period, with an $H H I$ index value of about 0.35 . It started to fall after the 1980 s and reached 0.171 in 1990 . It then displayed a steady and slow decline, reaching 0.046 in 2013.

(2) Volume of coal loaded: The $H H I$ index value for the volume of coal loaded declined steadily throughout the study period. It was 0.244 in 1973 and 0.118 in 2013 . Sudden increases in individual years were related to the expansion of the coal loading capacity in Qinhuangdao port. In particular, the "north output" pattern resulted in the $H H I$ index curve being higher than the other two curves.

(3) Volume of coal unloaded: The HHI index value for the volume of coal unloaded displayed a similar trend, but the decline was more obvious. It was very high in the $1970 \mathrm{~s}$, with a value of 0.785 in 1973 . In 1988, it declined to 0.28 . Thereafter it declined slowly and reached 0.036 in 2013. This was mainly due to the rapid expansion of coal unloaded from a few ports in the early part of the study period to most ports later in the study period. In other words, it was because coal unloading at coastal ports changed from a "south input" to an "all input" pattern. 


\subsection{The evolution of spatial agglomeration at regional ports}

The hinterland of each port has different natural and socio-economic properties. These differences, especially the industrial structure and distribution of coal resources, have important influences on the functioning of coal transportation and its developmental trend. It can also affect the overall characteristics and functional differences of regional ports. Although each group of regional ports considered in this study had the function of coal transportation, there were some differences in the functions of coal loading and unloading. This reflects the diverse relationship between regional development and coal supply and demand. As shown in Figure 5, there were significant differences in terms of the volume of coal loaded at each group of regional ports. Ports on the west bank of Bohai Bay have maintained an absolute dominant position in coal loading. Qinhuangdao, Huanghua, Jingtang, and Tianjin are all loading ports. And most of them are specialized coal ports. The proportion of coal loading continued to increase throughout the study period. It was $35.2 \%$ in 1973 and $75.5 \%$ in 2007 . In recent years, an expansion in the coal transport capacity occurred due to the Daqin, Shuohuang, and Houyue railways. The Houyue railway provides a direct line to customers, while Daqin and Shuohuang railways, corresponding to the ports at Qinhuangdao and Huanghua, respectively, are main lines that can accommodate materials arriving by ocean shipping. Therefore, the status of ports on the west bank of Bohai Bay has become more significant in the coal loading system. The Yangtze River Delta was an important coal loading area in the early 1970 s. The proportion of national coal loading undertaken here was $41.1 \%$ in 1978 , but thereafter it continually decreased, reaching $11.6 \%$ in 2007 . Shandong Peninsula was another important coal loading area whose contribution to the national total also declined. It was $20.3 \%$ in 1973 and $2.8 \%$ in 2013 . The volume of coal loaded in the Pearl River Delta, Beibu Gulf, southeast Fujian, and Liaodong Peninsula was small and stable, always being less than $5 \%$ of the national total.
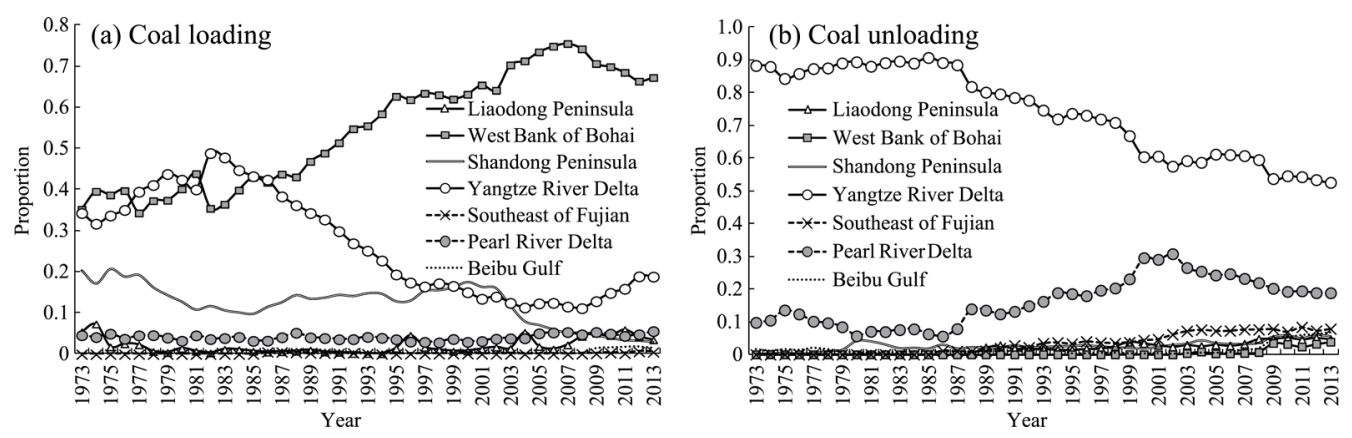

Figure 5 Proportion of all port groups involved in coal loading and unloading in China, 1973-2013

Unloading coal is a transportation function for most ports. Most of the coal unloading activity is concentrated in the Yangtze and Pearl River Delta. These two regions are not only the frontiers of China's reform and opening up program, but are also the country's new industrial bases. A large proportion of China's population, economic output, and urban spaces are concentrated here, while in comparison other regions have maintained low levels. For many years, the Yangtze River Delta was the main region of the country to where coal was transported. The region was responsible for a large proportion of the national coal unloading, 
but its importance in this regard has continued to decline. In 1973 it accounted for $88.2 \%$ of the national coal unloading, but this had declined to $52.5 \%$ by 2013. The Pearl River Delta is another important region of coal consumption, where the proportion of the national coal unloading increased at first and then decreased. It was $9.8 \%$ in $1973,30.7 \%$ in 2002 , and $18.8 \%$ in 2013. The volume of coal unloading in southeast Fujian was small, but its proportion of the national total has steadily increased from $1 \%$ in 1986 to $7.8 \%$ in 2013. Shandong and Liaodong peninsulas are important regions for coal loading, but their ports also have unloading functions. The proportion of the national coal unloading undertaken in these ports has fluctuated significantly, but with an increasing trend. They both increased from $0.3 \%$ to about $5 \%$ in 2013, which was mainly due to coal imports. As an area with few coal resources, the proportion of the national coal unloading undertaken at Beibu Gulf increased before the end of the 1970s. It reached $2.1 \%$ in 1977 , and then decreased to $0.3 \%$ in 2002. After a period of rapid growth, it reached $6.8 \%$ in 2013. The west bank of Bohai Bay is the main area of coal loading in China. The proportion of the national coal unloading undertaken in the region was tiny prior to the turn of the new century, but has increased significantly in recent years and reached $3.9 \%$ in 2013 . This growth is mainly due to the unloading of imported coal. The enhancement of the coal unloading function of northern ports has begun to gradually change the traditional functional pattern of ports in terms of coal transportation.

\section{Functional differentiation of coal transportation at China's coastal ports}

\subsection{Functional differentiation of coal transportation}

A port is a traffic node for loading and unloading, storage, and transportation of a variety of goods. Coal transportation is only one of the functions of a port. The intensity of this function reflects the level of specialization of the port toward coal transportation and the standard of the terminal facilities, which has a great effect on port facilities and the spatial structure of land use. We calculated the location quotient of each port according to the volume of coal loading and unloading and the results are shown in Figures 6 and 7.

The location quotient of coal loading reflects the intensity of each port in the function of outputting coal. There were four ports with a location quotient larger than 1 in 1973: Qinhuangdao, Lianyungang, Qingdao, and Shanghai. Qinhuangdao and Lianyungang had location quotients of 3.2 and 2.2, respectively, which indicates that they had significantly advantageous locations for coal loading. There were a few scattered ports with a location quotient less than 1. In 1986, 1995, and 2005, the number of ports with a location quotient larger than 1 was eight. The location quotient for Qinhuangdao and Rizhao was always larger than 2, and these ports maintained a dominant position in coal loading. In the mid-1980s, there was an obvious differentiation in coal loading between the north and the south. Ports with a location quotient lower than 1 were mainly distributed south of the Yangtze River. The "north output" pattern was obvious. Thereafter, some specialized coal ports (e.g., Jingtang and Huanghua) emerged, and became the main coal loading ports in addition to Qinhuangdao and Rizhao. In 1995, the advantages of coal loading in the Yangtze River Delta weakened, while they were strengthened for a small number of ports in south China. The spatial mode of loading in the northern ports did not change. The spatial pattern of 2005 was strengthened 


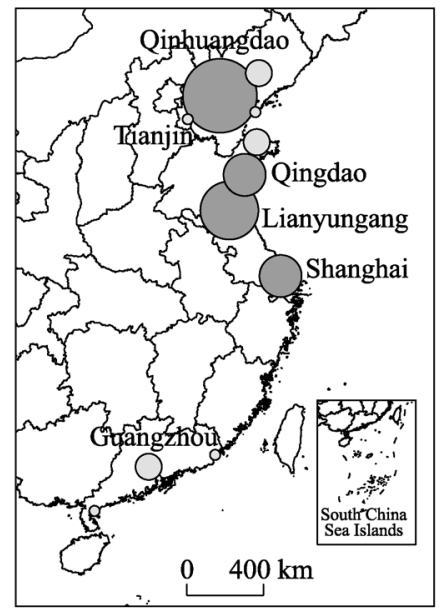

(a) 1973

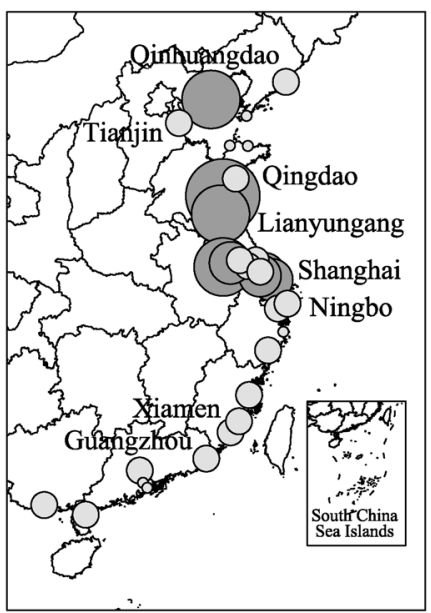

(b) 1986

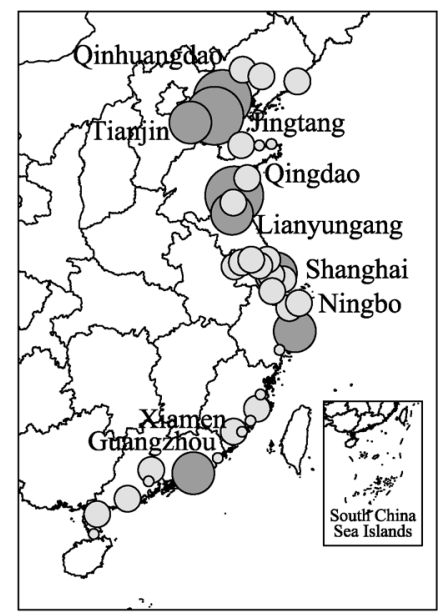

(c) 1995

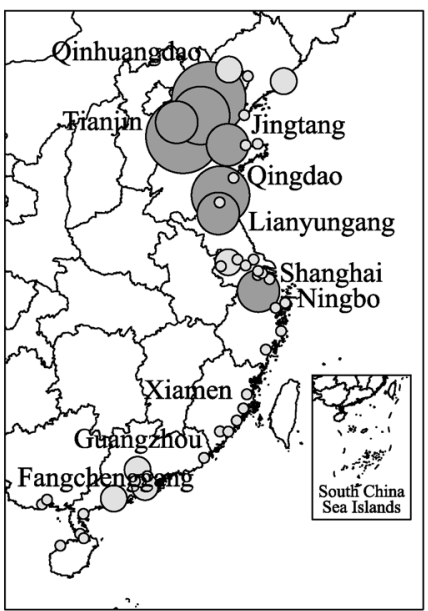

(d) 2005

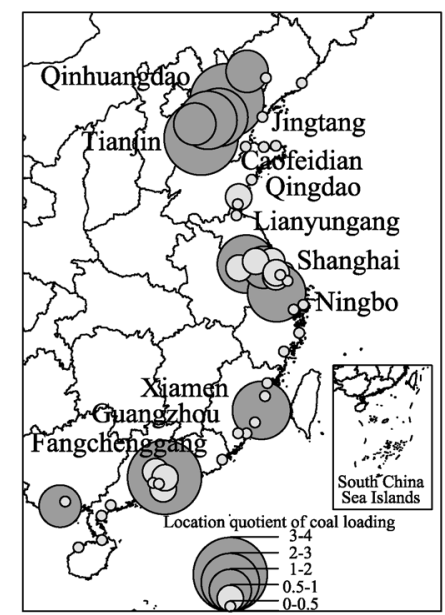

(e) 2013

Figure 6 Spatial pattern and evolution of the location quotients of coal loading at coastal ports in China

compared with 1986. The advantages of Bohai Bay for coal loading were strengthened, while the area south of the Yangtze River Delta was weakened. The spatial differentiation of coal loading became more prominent over the study period. In 2013, ports whose location quotient was larger than 1 and smaller than 1 were distributed in intervals. There were 12 ports with a location quotient larger than 1 , accounting for $1 / 5$ of all ports. The area served by these ports expanded, and some ports in southeast Fujian and Beibu Gulf had obvious advantages in coal loading. Ports whose location quotient was lower than 1 were mainly distributed in the west of Liaoning Province, Shandong Peninsula, the south of Zhejiang Province, the south of Fujian Province, and the east of Guangdong Province. The ports of Huanghua, Qinhuangdao, and Machong had the most prominent coal loading function, with a location quotient larger than 3. Huanghua is a specialized coal port and mainly transports coal from Shenfu coalfield. Coal accounts for $98 \%$ of the loading volume in Huanghua. Qinhuangdao is the world's largest coal loading port and mainly transports coal from the Datong Coal Mining Group. Its volume of coal loading was 240 million tons in 2013, accounting for $30 \%$ of the national total. The location quotients of Putian, Jingtang, 


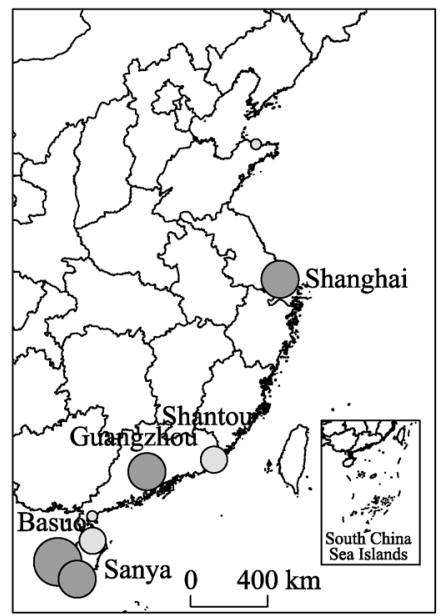

(a) 1973

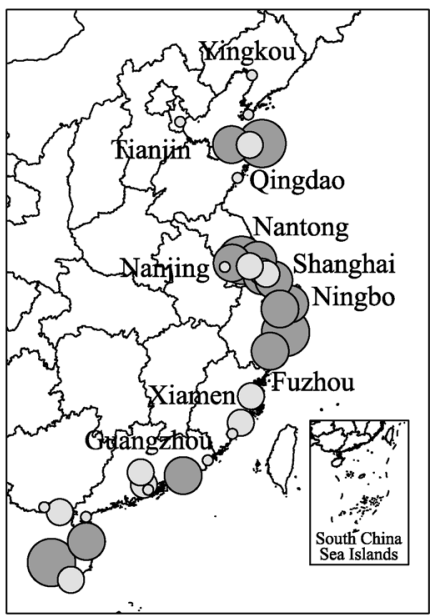

(b) 1986

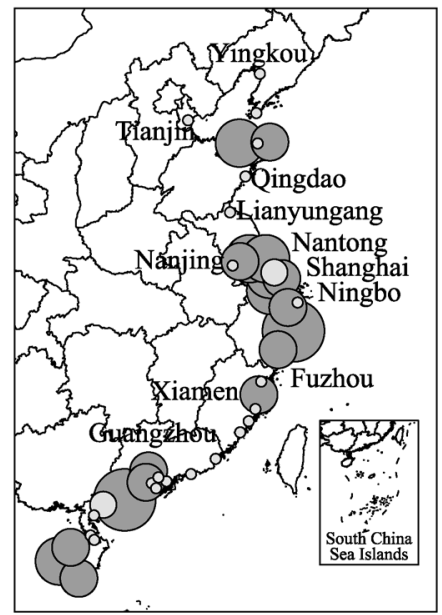

(c) 1995

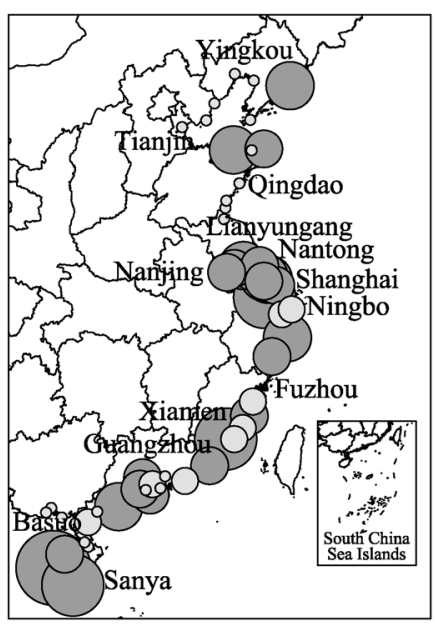

(d) 2005

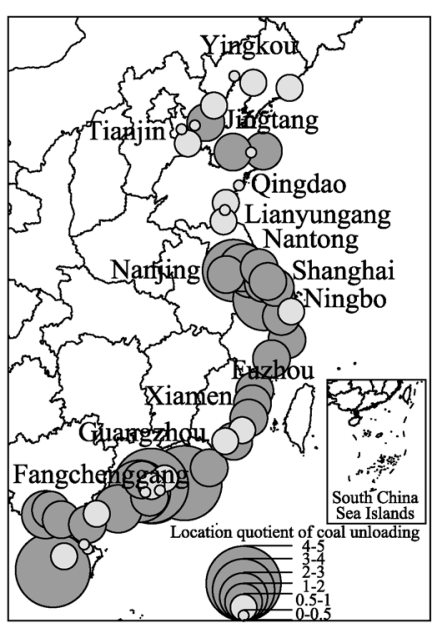

(e) 2013

Figure 7 Spatial pattern and evolution of the location quotients of coal unloading at coastal ports in China

Caofeidian, Yangzhou, and Jiaxing were between 2 and 3, while the values for Jiangyin, Fangchenggang, Tianjin, and Jinzhou were larger than 1. On the north coast, the prominent coal loading ports were distributed in a cluster, while some individual coal loading ports such as Putian and Machong were located on the south coast. Although the volume of coal loaded at these two ports was small, it represented a large proportion of the total material loaded at the ports. The spatial pattern changed from a "north-south differentiation" to a "space interval" mode. Ports on the north coast have group advantages, while the southern coastal ports have individual advantages.

The location quotient of coal unloading ports reflects the inputting function of each port. Basuo, Shanghai, Guangzhou, and Sanya had values larger than 1 in 1973 and were all located south of the Yangtze River. The number of prominent coal unloading ports increased to 14 in 1986. The unloading function of ports in the Yangtze River Delta, northern coastal ports, and ports in Hainan Province was strengthened. Ports whose location quotients were lower than one were mainly distributed in Liaodong Peninsula, the west bank of Bohai Sea, 
south of Shandong Peninsula, southeast of Fujian, the Pearl River Delta, and Beibu Gulf. In 1995, there were 19 ports with a location quotient larger than 1. Among them, Taizhou and Yangjiang were larger than 3 and their coal unloading advantages were obvious. Ports with quotients larger than 2 were mainly located in the Yangtze River Delta, the Pearl River Delta, and Shandong Peninsula. Ports with a location quotient less than 1 were mainly distributed in the Liaodong Peninsula, the west bank of Bohai Bay, Shandong Peninsula, northern Jiangsu, southeast Fujian, and eastern Guangdong. In 2005, the number of ports whose location quotients were larger than 1 further increased to 25. Among them, Basuo was larger than 4, while Zhangzhou, Jiaxing, and Sanya were larger than 3. The coal unloading advantages in southeast Fujian became apparent. The Yangtze River and the region to the south formed a continuous area where coal unloading was dominant. In 2013, all coastal ports had a coal unloading function, but for most of them there were only minor advantages over other activities, and therefore they were not specialized coal unloading ports. The number of ports with a location quotient larger than 1 was 33. Taiping, Basuo, Shanwei, and Machong had quotients greater than 4 , and had the largest capacity for coal unloading. Taiping and Machong are small ports in the Pearl River Delta, each with a well-developed coal unloading function, but only small quantities of coal are unloaded. They mainly supply coal to nearby power plants. Coal unloaded at Shanwei is also mainly supplied to local power plants. Ports whose location quotients were less than 1 gradually emerged in the area around Bohai Bay. Jingtang, Weihai, Longkou, and other Bohai Sea ports all had location quotients less than 1. Tianjin, Qingdao, Jinzhou, Lanshan, Dalian, and Caofeidian did not have any advantages for coal unloading, because their location quotients were less than 0.3. The unloading advantages of ports around Bohai and south of the Shandong Peninsula were strengthened, but their location quotients were still lower than 1. From the above analysis, it was found that although the unloading pattern of coastal ports changed from a "south input" to "all input", ports with an obvious unloading advantage were still concentrated south of the Yangtze River.

\subsection{Relationship between coal loading and unloading at coastal ports}

The location quotient is a macroscopic judgment of the advantages of coal transportation, but it cannot identify the relationship between coal inputs and outputs, which determine a port's status in the coal transportation system. If we only consider the proportion of coal loading undertaken at each port, they can be broadly divided into loading ports, unloading ports, and comprehensive ports (Table 1). Based on experience, we classified ports with an $R_{i}$ larger than 0.6 as coal loading ports, ports with an $R_{i}$ less than 0.4 as coal unloading ports, and ports with an $R_{i}$ between 0.4 and 0.6 as comprehensive ports. Using this classification, there are only six coal loading ports in the coastal areas of China, accounting for about 1/10 of the ports considered in this study. Five ports are comprehensive ports, accounting for about $1 / 12$ of the total studied, and 46 ports are coal unloading ports, accounting for $4 / 5$ of the total studied. This structure confirms that coal loading is mainly concentrated in a small number of ports, most of which are coal unloading ports, which is consistent with the above analysis.

Coal loading as a proportion of total port activity at Qinhuangdao, Tianjin, Huanghua, Jinzhou, Caofeidian, and Jingtang is very high, being larger than $95 \%$ at the first four ports. 
These ports are typical coal loading ports (Table 1) and handle a volume of more than 10 million tons, which means they are large coal output ports. They are mainly located in the area around Bohai Bay, especially on the west bank of the bay. Coal loading ports have the characteristics of a high proportion of coal loading as a proportion of total port activity, large scale, and a northern location.

Table 1 Classification of coastal ports in China according to their coal loading and unloading activity

\begin{tabular}{|c|c|c|c|}
\hline Category & $\begin{array}{l}\text { Proportion of } \\
\text { loading }(\%)\end{array}$ & Name of port & Number \\
\hline \multirow{3}{*}{$\begin{array}{l}\text { Coal loading } \\
\text { ports }\end{array}$} & $90-100$ & Qinhuangdao, Tianjin, Huanghua, Jinzhou, Caofeidian & 5 \\
\hline & $60-90$ & Jingtang & 1 \\
\hline & $40-60$ & Zhoushan, Rizhao, Machong, Yangzhou, Lianyungang & 5 \\
\hline \multirow[t]{3}{*}{$\begin{array}{l}\text { Comprehensive } \\
\text { ports }\end{array}$} & $30-40$ & $\begin{array}{l}\text { Qingdao, Nantong, Dandong, Dalian, Shatian, Yantai, } \\
\text { Guangzhou, Jiangyin, Nanjing }\end{array}$ & 9 \\
\hline & $20-30$ & $\begin{array}{l}\text { Zhuhai, Zhangjiagang, Shanghai, Putian, Fangchenggang, } \\
\text { Jiaxing, Zhenjiang }\end{array}$ & 7 \\
\hline & $10-20$ & Changshu, Longkou, Weihai, Yingkou, Ningbo, Taicang & 6 \\
\hline \multirow[t]{2}{*}{$\begin{array}{l}\text { Coal unloading } \\
\text { ports }\end{array}$} & $0-10$ & $\begin{array}{l}\text { Lanshan, Fuzhou, Xiamen, Qinzhou, Haikou, Zhongshan, } \\
\text { Haian, Zhangzhou, Taizhou, Jiangmen, Quanzhou, Wen- } \\
\text { zhou, Maoming, Yangpu, Ningde, Shantou }\end{array}$ & 16 \\
\hline & 0 & $\begin{array}{l}\text { Basuo, Beihai, Zhanjiang, Yangjiang, Taiping, Shenzhen, } \\
\text { Huizhou, Shanwei }\end{array}$ & 8 \\
\hline
\end{tabular}

Zhoushan, Rizhao, Machong, Yangzhou, and Lianyungang are all coal loading and unloading ports. The differences in coal loading and unloading as a proportion of total port activity at these ports were not significant. They are located in the area between the Yangtze River and Shandong Peninsula. This type of port can be further divided into two categories. The first category is coal transit ports, and includes Zhoushan, Machong, Lianyungang, and Yangzhou. The coal transfer terminal of Zhoushan is in Liuheng Island. It is the largest coal transit base in east China and mainly transfers coal from the northern ports to the south of Zhejiang Province. The Haichang terminal at Machong is the largest coal transit base in south China. It unloads domestic and international coal and then transfers it to Zhongshan, Huizhou, Foshan, Guangzhou, and Dongguan. Lianyungang is an important transit port for thermal coal. It has built a large coal transit base together with the Shenhua Group and mainly transfers coal from Shaanxi Province to northern Jiangsu. Yangzhou is an important node of coal transportation along the Yangtze River. The coal demand from the four provinces in the middle reaches of the Yangtze River has grown rapidly; therefore, "sea-river transport" and "rail-sea transport" have been used as supplements to the existing coal supply system. The northern coal travels to the port of Yangzhou and is then transferred along the Yangtze River to areas in the middle reaches. The second category is ports that undertake not only coal loading, but also coal unloading due to the surging coal imports. Rizhao belongs to this category and imports coking coal from Australia, Russia, North Korea, and Indonesia to supply its steel plants and its deep hinterland.

The remaining ports are considered to be coal unloading ports, especially those in the Pearl River Delta. Basuo, Beihai, Zhanjiang, Yangjiang, Taiping, Shenzhen, Huizhou, and Shanwei, are all solely coal unloading ports. These ports are located in the Pearl River Delta 
and Beibu Gulf. The largest volume of coal (more than eight million tons) is unloaded at Taiping and Yangjiang, while the scale of the other ports is small. There are 16 ports where coal unloading as a proportion of total port activity is between $0.1 \%$ and $10 \%$, including Lanshan, Fuzhou, Xiamen, and Qinzhou. These ports are mainly distributed in southeast Fujian and further southwards. Among them, Fuzhou, Xiamen, Wenzhou, Zhanjiang, Shantou, and Taizhou unload more than 15 million tons. Coal unloading as a proportion of total port activity at Changshu, Longkou, Weihai, Yingkou, Ningbo, and Taicang is between $10 \%-20 \%$. These ports are distributed in the Yangtze River Delta and the northern region. Coal unloading as a proportion of total port activity at Zhuhai, Zhangjiagang, Shanghai, Putian, Fangchenggang, Jiaxing, and Zhenjiang is between $20 \%-30 \%$, and these ports are scattered throughout the country. Shanghai is a large coal unloading port, with a volume exceeding 80 million tons. Coal unloading at Qingdao, Nantong, Dandong, Dalian, Shatian, Yantai, Guangzhou, Jiangyin, and Nanjing accounts for $30 \%-40 \%$ of port activity, and these ports are mainly located in areas north of the Yangtze River. Qingdao, Dalian, and Yantai have changed from traditional coal loading ports to coal unloading ports. The reason for this at Qingdao and Yantai is the construction of coastal steel plants, which has led to a large volume of coking coal being imported. The reason for the change at Dalian is due to the construction of coal hub for northeast China and the volume of coal unloaded for domestic trade has increased significantly. Although half of the volume unloaded is destined for the local market, it is still classed as a coal unloading port.

From the perspective of spatial distribution, ports with a high proportion of coal loading are concentrated on the west bank of Bohai Bay. Coal loading as a proportion of port activity is very low in Liaodong Peninsula, north of Shandong Peninsula, southeast Fujian, Beibu Gulf, the Pearl River Delta and the Yangtze River Delta. These ports are mainly involved in coal unloading. A clear spatial dislocation has formed, reflecting the spatial relationship between the input and output of coal resources. The distribution of coal resources is uneven. There are more resources in the west and north, but fewer in the east and south. However, east and south China have experienced rapid economic growth over a long period. They are the areas with the strongest demand for coal and need to receive large amounts of coal. In recent years, the capacity and output of thermal power production, metallurgy, flat glass, cement, and other high energy consuming industries in the southeast coastal area has expanded rapidly. The thermal power installed capacity, power generation and thermal power enterprises account for half of the national total. Together, Jiangsu, Shandong, Guangdong, and Zhejiang account for nearly one third of the national total. These thermal power enterprises have directly invested in wharfs, and a large number of specialized coal wharfs have been constructed. Therefore, the spatial difference between the coal base and coal consumption is an important factor in the formation of a port's coal transportation pattern.

From the time series, the evolution of six types of port coal transportation function was apparent (Table 2). There were six ports that had always been coal loading ports: Qinhuangdao, Tianjin, Huanghua, Jinzhou, Caofeidian, and Jingtang. These ports are mainly concentrated around the Bohai Sea, especially the west bank of Bohai Bay. They function as the loading gateway of the hinterland. There were 32 ports that had always been coal unloading ports, accounting for $57 \%$ of the national total. In addition to Weihai and Longkou, they are all distributed to the south of the Yangtze River. The energy demand promoted by industri- 
alization and urbanization in the hinterland of these ports has led to the establishment of their particular characteristics. There are some ports whose function transferred from loading to unloading over the period studied, which reflects the changes in regional coal demand and the ports' positioning in the coal transportation network. The function of 12 ports in the area around Bohai Bay transferred from loading to unloading. These ports changed their transport function in the mid-1990s. Coal loading as a proportion of total port activity at Dandong, Dalian, and Qingdao reduced from $100 \%$ to $35 \%$, and at Yingkou reduced from $100 \%$ to $10 \%$. The main reason for this was the development of the iron and steel industry in the hinterland, which resulted in an increased demand for coal. It not only consumed the volume of coal that was traditionally loaded at these ports, but also required an input from other areas. Therefore, the traditional "south input and north output" became an "all input and north output" pattern, and most of the additional coal inputs were derived from international imports. Zhangjiagang and Jiangyin changed from comprehensive ports to unloading ports. They are both located in the Yangtze River Delta, where the coal transit function weakened. Zhoushan, Machong, and Yangzhou, also located in the Yangtze River Delta, changed from unloading ports to comprehensive ports. Coal transfer terminals were constructed at these ports. Rizhao and Lianyungang changed from unloading ports to comprehensive ports. The former resulted from a surge of coal imports, while the latter was caused by the development of a coal transshipment base. Overall, the loading function of China's coastal ports weakened, and the unloading function was enhanced. No ports changed from unloading ports to loading ports, which was determined by the stable distribution of coal resources.

Table 2 Evolution of the transportation function of China's coastal ports

\begin{tabular}{llc}
\hline \multicolumn{1}{c}{ Characteristics } & \multicolumn{1}{c}{ Name of port } & Number \\
\hline $\begin{array}{l}\text { Always been coal loading ports } \\
\text { Always been coal unloading ports }\end{array}$ & $\begin{array}{l}\text { Qinhuangdao, Tianjin, Huanghua, Jinzhou, Caofeidian, Jingtang } \\
\text { Basuo, Beihai, Yangjiang, Taiping, Shenzhen, Huizhou, Shanwei, } \\
\text { Qinzhou, Haikou, Zhongshan, Haian, Zhangzhou, Taizhou, Ji- } \\
\text { angmen, Quanzhou, Wenzhou, Maoming, Yangpu, Ningde, Shan- } \\
\text { tou, Longkou, Changshu, Weihai, Ningbo, Zhuhai, Shanghai, }\end{array}$ & 32 \\
& $\begin{array}{l}\text { Putian, Jiaxing, Zhenjiang, Nantong, Shatian, Guangzhou } \\
\text { Zhanjiang, Lanshan, Fuzhou, Xiamen, Yingkou, Taicang, Fang- } \\
\text { chenggang, Qingdao, Dandong, Dalian, Yantai, Nanjing }\end{array}$ & 12 \\
$\begin{array}{l}\text { Transferred from loading ports to } \\
\text { unloading ports }\end{array}$ & $\begin{array}{l}\text { Zhangjiagang, Jiangyin } \\
\text { Transferred from comprehensive } \\
\text { ports to unloading ports } \\
\begin{array}{l}\text { Transferred from unloading ports } \\
\text { to comprehensive ports }\end{array}\end{array}$ \\
$\begin{array}{l}\text { Transferred from loading ports to } \\
\text { comprehensive ports }\end{array}$ & Rizhao, Lianyungang & 2 \\
\hline
\end{tabular}

\section{Conclusions and discussion}

In this study, we used coal throughput, and the loading and unloading volume to study the spatial evolution of coal transportation at China's coastal ports. We found that since the 1970s, the number of coastal ports engaged in coal transportation has increased, and the throughput and area served by the coal ports has expanded. The "north output" pattern did not change, with coal loading always located north of the Yangtze River, and especially on the west bank of Bohai Bay. Coal unloading ports were initially located in the south, but this 
activity gradually expanded to all ports. In other words, the spatial distribution changed from a "south input" to an "all input". With the expansion in the area covered by ports, unloading coal has become a transportation function of most coastal ports. The coal transport mode of China's coastal ports has changed from a "south input and north output" to an "all input and north output" pattern, but the prominent coal unloading ports are still concentrated in the south of the Yangtze River. The phenomenon whereby most of the coal throughput, and the loading and unloading of coal were concentrated in a small number of ports gradually dissipated. This was mainly due to the increase in the number of ports in the early stage of the period studied and the fluctuations in volumes of coal handled at ports in the later stage. Since the early 1990s, the degree of agglomeration of coal loading was always higher than the degree of agglomeration of coal unloading and the total throughput. Ports on the west bank of Bohai Bay maintained an absolute dominance in coal loading. Due to the development of the steel industry in the hinterland of these ports, the demand for coal has increased and some traditional coal loading ports, such as Qingdao and Yantai, have become unloading ports. Overall, the coal loading function of coastal ports has weakened, and the unloading function has been enhanced, which is determined by the stability of coal distribution.

Due to severe environmental and resource management problems, China issued a series of regulations (e.g., 10 air pollution control measures) optimizing the industrial structure of the southeastern coastal area. Industries with high pollution potential, high energy consumption, and high emissions are strictly controlled, and innovation-driven and technology leading industry is encouraged. The coal consumption of the Jing-Jin-Ji (Beijing-Tianjin-Hebei) region, the Yangtze River Delta, and the Pearl River Delta is also controlled, and therefore the demand for coal has been curbed to a certain extent. At the same time, due to economic development and resource security concerns, China controls coal imports through a tariff lever. From October 15th, 2014, China cancelled the zero import tariff and resumed the most favored nation tariff. This will affect the pattern of coal transportation, and restore the "south input and north output" pattern to some extent. Because of data limitations, we only analyzed coal transportation data at set points in detail, and did not consider the overall network which can more accurately reflect a port's coal source and flow. In addition, the coupling relationship between coal transportation and the distribution of thermal power enterprises, coking coal transportation, and the distribution of steel enterprises should be investigated. Coal transportation at inland ports, and the evolution of coal imports and exports should also be studied.

\section{References}

Ash L, Waters C D J, 1991. Simulating the transport of coal across Canada: Strategic route planning. Journal of the Operational Research Society, 42(3): 195-203.

Cai G T, Zhang L, 2006. Analysis basic situation of China's energy security. Progress in Geography, 25(5): 57-66. (in Chinese)

Che L L, Han X, Qin X N et al., 2014. Inter-regional flow and completion of coal in China based on Niche Theory. Resources Science, 36(10): 2215-2222. (in Chinese)

Cheng S K, Xu Z R, Shen L, 2008. Spatial-temporal process and driving force of interprovincial coal flowing in China. Acta Geographica Sinica, 63(3): 603-612. (in Chinese)

Dong X C, Wang G X, 2012. Coal logistics competency strategies for ports in the Tianjin and Hebei regions 
around the Bohai Bay in China. Energy Procedia, 17: 436-443.

Elmes G, 1984. Coal transportation: An undervalued aspect of energy modeling? Transportation Research Part A: General, 18(1): 13-23.

Ji H W, Zhao Y, 2014. The accessibility spatial pattern of coal railway transport network in China. Areal Research and Development, 33(1): 6-11. (in Chinese)

Jiang W, Gao W D, Zhang M, 2013. China coal resource railway circulation network's structural characteristic and evolvement. Economic Geography, 33(1): 98-104. (in Chinese)

Kania J J, 1984. Economics of coal transport by slurry pipeline versus unit train: A case study. Energy Economics, 6(2): 131-138.

LeBlanc M R, Kalter R J, Boisvert R N, 1978. Allocation of United States coal production to meet future energy needs. Land Economics, 54(3): 316-336.

Liu J P, Yang H, He G W et al., 2013. Study on optimization of coal transport corridors lay-out in China. China Coal, 39(10): 15-20. (in Chinese)

Liu S, Tian L X, Huang Y S, 2014. A comparative study on prediction of throughput in coal ports among three models. International Journal of Machine Learning and Cybernetics, 5(1): 125-133.

Ma B B, Lu C X, Zhang L et al., 2010. The temporal and spatial patterns and potential evaluation of China's energy resources development. Journal of Geographical Sciences, 20(3): 347-356.

Ma L, Jin F J, 2014. Analysis of the spatial pattern and main driving factors of China's coal self-sufficiency rate. Economic Geography, 34(7): 90-96. (in Chinese)

Todd D, 1997. China's energy needs, coal transfers and the ports sector. Geoforum, 28(1): 39-53.

Wang C J, Ducruet C, 2014. Transport corridors and regional balance in China: The case study of coal trade and logistics. Journal of Transport Geography, 40: 3-16.

Wang C J, Mo H H, Wang J E, 2009. Regularity and pattern of Chinese coal resources flow field. Journal of Natural Resources, 24(8): 1402-1411. (in Chinese)

Wang J L, Feng L Y, Davidsson S et al., 2013. Chinese coal supply and future production outlooks. Energy, 60(7): 204-214.

Wang W, Wang C J, 2014. Pattern evolution and dynamic mechanism of coal transportation for the ports around Bohai. Journal of Natural Resources, 29(11): 1916-1929. (in Chinese)

Wang Y Q, Zhao Y, 2014. Spatial pattern evolution and inner differences of source-sink regions of China's coal resources flow. Scientia Geographica Sinica, 34(10): 1153-1160. (in Chinese)

Wei B C, 2008. Study on layout optimization of coal transport corridor [D]. Beijing: Beijing Jiaotong University. (in Chinese)

Yang M, 2011. Research on coal transportation development of Qinhuangdao port [D]. Dalian: Dalian Maritime University. (in Chinese)

Yu L, Jin F J, Zhang B, 2006. The present situation, development trend and countermeasures of China coal transports. Railway Transportation Economy, (5): 38-41. (in Chinese)

Yu Q, 2012. Research on Tianjin port coal transportation development [D]. Dalian: Dalian Maritime University. (in Chinese)

Zaklan A, Cullmann A, Neumann A et al., 2012. The globalization of steam coal markets and the role of logistics: An empirical analysis. Energy Economics, 34(1): 105-116.

Zhang L, Huang Y X, Yang B et al., 2012. Time-space coordination of national energy supply. Journal of Natural Resources, 27(4): 529-539. (in Chinese)

Zhao Y, Yu P, 2007. The spatial pattern of coal flow and flowing channel in China. Economic Geography, 27(2): 196-200. (in Chinese) 